\begin{tabular}{|ccc|}
\hline & ANNALES INSTITUTI SLAVICI \\
& UNIVERSITATIS DEBRECENIENSIS & \\
SLAVICA XLIX & 2020 & DEBRECEN \\
\hline
\end{tabular}

Дмитрий РЕУТ

\title{
ЭПОХА ПОСТ-ПРАГМАТИЧЕСКИХ СТРАТЕГИЙ
}

«Лис знает много секретов, а ежодин, но самый главный»

Архилох (7 в. до н.э.)

\section{Era of Post-Pragmatical Strategies}

\begin{abstract}
An extended definition of culture as a phenomenon that includes processes and results of human communities interaction with wildlife, e.g. viruses is propounded. An indicator of development limitations of Global civilization-cultural integrity is proposed. We put forward the concept of a post-pragmatic strategy of a cultural unit. The latter signifies social integrity that represents a separate culture - a stable set of traits, categories, patterns reproduced in series of generations. We believe a cultural unit to be a large-scale system. Our study is carried out in the context of the emerging intellectual discipline Hygiene of Culture with the help of methodology of sustainable reproduction of a cultural unit. The aim of the study is to form methodological bases for the reaction of cultural unit aimed at confronting phenomena similar to COVID-19. The result is altruistic post-pragmatic strategy, free of mistrust. We propose to supplement the known security dilemma as follows. Actors allocate their military budgets in proportion to confidence/mistrust rates to opponents while likelihood of risk events in the environment increases according to sandpile model and information noise rises.
\end{abstract}

Keywords: cultural unit, security dilemma, trust, hygiene of culture, COVID-19

Взрывной рост числа негативных событий в мире, нарушающий status quo, выводит сегодняшнего наблюдателя и участника (как индивидуального, так и коллективного субъекта) в рефлексивную позицию.

Она позволяет видеть, что человечество в целом оказалось по отношению к происходящему в режиме догоняющего и неизменно отстающего понимания. Конечно, понимание феноменов окружающего мира является вечной проблемой. Ее усугубляет скорость происходящих изменений. По опыту мы знаем, что ее разрешению (хотя бы временному и частичному) способствует расширение контекста рассмотрения проблемы. Естественно будет прибегнуть к этому приему и сейчас.

Наиболее широким из известных нам сегодня является контекст становящейся интеллектуальной дисциплины «гигиена культуры» с развивающимся в ее рамках инструментарием методологии культурной единицы (методологии четвертого типа, названной так в развитие классификации В.М. Розина [РОзин 2005]).

Библиография гигиены культуры пока обозрима, она состоит из десятка сборников трудов Международных конференций и коллективных монографий 
(эту часть библиографии мы выделили в отдельное ПРИЛОЖЕНИЕ) плюс ряд публикаций в журнале Slavica и других периодических изданиях. Указанные книги (в большинстве - двуязычные) доступны в Ассоциации «За венгерскороссийское сотрудничество имени Л.Н. Толстого», библиотеках крупнейших университетов и Российской государственной библиотеке.

Объект исследования гигиены культуры вообще и настоящей работы в частности - культура. Обычно она понимается как «совокупность всех надбиологических форм жизнедеятельности человека и их результатов» [КАГАН 1966: 29].Но даже в такое, казалось бы, фундаментальное определение жизнь вносит свои коррективы, на этот раз в духе «транс-анти-гуманизма». Мы имеем в виду так или иначе возникшие биологические угрозы, например, вирус COVID-19. Бесспорно, они влияют на многие культурные феномены. В связи со сказанным мы предлагаем дополнить приведенное выше определение [КАГАН 1966: 29] следующим образом.

Культура есть совокупность всех надбиологических форм жизнедеятельности человека и их результатов, включая формируемые с участием естественно происходящего или/и искусственно организуемого взаимодействия живой природной среды - в ее естественных или искусственно культивируемых проявлениях - с человеком.

Предмет исследования- наиболее важные (с нашей точки зрения, сформировавшейся к середине апреля 2020 года) аспекты способа существования культурных единиц и их совокупностей, способствующие устойчивости их воспроизводства. Они служат отправной точкой применения методологии устойчивого воспроизводства культурной единицы к пониманию текущей повседневности и грядущих перспектив. Предмет исследования настоящего направления работ конкретизируется ниже.

Культурная единица в нашем понимании - это система, различимая на культурном фоне методами культурологии или/и изучающих отдельные ее подсистемы дисциплин. Культурная единица, как правило, воспроизводится на сменном человеческом материале, поэтому она подвержена изменениям. Культурная единица обладает устойчивостью, достаточной, чтобы успевать применять к ней культурологический инструментарий. Культурная единица может погибнуть вследствие социальных и/или природных катаклизмов. Культурная единица может трансформироваться в одну или несколько новых культурных единиц, либо давать начало «разветвлениям». Эти культурные феномены могут фиксироваться конвенционально и получать индивидуальные имена (подобно периодам итальянского Ренессанса). Культурные единицы способны взаимодействовать («столкновение цивилизаций» по Хантингтону [ХАНТингтон 2003]). Подробнее понятие культурной единицы обсуждается в ряде работ [РеУт 2017; РЕУт 2019а: 72-98; РеУт 2019б]. Заметим, что в последнем источнике редакторы в большинстве случаев заменил термин «культурная единица» на «культурная система», как более распространенный в русскоязычной литературе. Термин «культурная единица» несет специфическую акцентировку (с коннотациями «единица исследования», «сущность в ряду 
многих подобных сущностей» и т.д.), хотя, конечно, системный подход к ее изучению вполне правомерен и в большинстве случаев предпочтителен.

Так, иногда бывает удобно видеть в культурной единице крупномасштабную систему. «Мы предлагаем в ходе социокультурных исследований различать несколько классов подсистем Глобальной системы, соответствующих следующим аспектам теоретической действительности: 1) хозяйственно-экономической деятельности, 2) социальной деятельности, 3) пространству истории, 4) пространству геополитических конфигураций, 5) пространству культурной интеграции, 6) планетарному пространству» [РЕУт 2020]. Критерием отнесения подсистемы деятельности и осуществляющего ее субъекта к тому или другому классу служит проверка его локальной состоятельности. Он должен быть в состоянии обеспечивать в течение всего времени своей деятельности протекание базовых процессов, соответствующих рассматриваемому аспекту (слою) совокупной системы. Крупномасштабная система есть совокупность двух или более «нарисованных друг на друге» подсистем, принадлежащих различным ее классам (слоям). Число принимаемых в рассмотрение слоев зависит от интересов исследователя.

В качестве примера крупномасштабной системы может быть рассмотрена современная война. Э. Люттвак выделяет 5 уровней войны [ЛЮТТВАК 2012], К. Грей - 17 «размерностей», воздействующих друг на друга [GRAY 1999].

В настоящее время нестабильность среды обитания человека возрастает. Пример - пандемия COVID-19. Нестабильность среды активизирует способность как человека, так и культурной единицы в целом к адаптации. Может потребоваться трансформация некоторых аспектов способа существования культурных единиц и их совокупностей. Одним из таких аспектов является стратегия культурной единицы. Цель настоящей работы - детализация методологии культурных единиц и их совокупностей в отношении выбора класса предпочтительных стратегий, их разработки и реализации.

Какова бы ни была реальная история COVID-19, приходится констатировать, что в ходе пандемии и сопутствующих хозяйственно-экономических «рикошетов» крупные страны понесли беспрецедентные потери. Следовательно, рассматриваемая проблема является значимой.

ЛПР (лица, принимающие решения) в составе крупных институций и культурных единиц, имеющие доступ к ресурсам - адресаты результатов наших исследований - вероятно, согласятся, что при любом сценарии возникновения и развития пандемии на ее ход некоторым образом влияли и влияют решения, принимаемые и реализуемые на разных уровнях крупномасштабных систем в разное время.

Каковы основания для подготовки и принятия решения? С одной стороны, это - фактически складывающаяся ситуация, с другой стороны - стратегия культурной единицы. Что является исходным пунктом в этом процессе? Каково должно быть направление движения - снизу вверх или сверху вниз? Мы следуем концепции сложностного мышления Э. Морена [МОРЕН 2005], предлагающего начало движения от сложного к простому с последующим переходом к челночному движению. Таким образом, вопрос о конкретизации предмета 
исследования мы решаем в пользу стратегии культурной единицы, разработанной и осуществляемой под руководством ее ЛПР.

Что составляет содержание стратегий крупных культурных единиц (например, «странового» масштаба?) Широкий обзор соответствующих публикаций представлен в монографии [АРЗУМАНЯН 2011]. Ее библиографический список содержит 559 позиций, в основном, англоязычных. В книге сопоставляются основные доктрины военной стратегии: концепция Сунь-Цзы, Н. Макиавелли, К. фон Клаузевица, Наполеона, Х. Мольтке-старшего, А. де Жомини, Дж. Корбетта, Л. Гарта, М. Говарда, Э. Люттвака, М. ван Кревельда, К. Грея, современная концепция сетецентрических войн, включая доктрину «мощь на кромке», а также претендующие на их обобщение представления, бытующие в современных американских военных руководствах.

При этом единого общепринятого определения стратегии в современном культурном дискурсе не существует.

Согласно популярному определению, даваемому в учебниках U.S. Army War College, стратегия - это «искусная формулировка, координация и применение целей (задач), способов (путей, методов), действий и средств (обеспечивающих ресурсов) для укрепления и защиты национальных интересов» [CHILCOAT 2001]. Мы цитируем это определение не потому, что оно представляется нам наиболее удачным, но потому, что оно маркирует мейнстрим современных стратегических представлений.

Концентрируясь на концептуальном аспекте вопроса, мы можем полагать, что стратегия есть более или менее пространная формулировка способа достижения целей индивидуумом или коллективом в природной и/или социальной среде на том или ином уровне ее агрегирования/рассмотрения.

Разразившаяся ныне пандемия COVID-19 по факту (вне зависимости от возможного осуществления предварительных конспирологических сюжетов) не отвечает интересам ни одной крупной нации, способной в принципе осуществить масштабную программу конструирования вирусов. Всем странам пришлось срочно разрабатывать и вводить затратные чрезвычайные меры. Вывод: регулярные рабочие стратегии государственного масштаба стран очерченного круга оказались неэффективными.

Отдельного рассмотрения заслуживает вопрос о рабочей стратегии «странового» уровня в случае вероятного возникновения военных конфликтов малой интенсивности [ТОФФЛЕР 2005, КРЕВЕЛЬД 2005], тесно связанный с развитием средств массовой коммуникации. Вследствие их развития граница между миром и войной становится все более размытой. Если «безопасность» в мире ядерного оружия базировалась на гарантированном мгновенном взаимном уничтожении, то признаки начала войны или серии войн малой интенсивности отсутствуют. Это заставляет обратить внимание на стратегию мирного времени. Интересно, что она была предметом исследования древних авторов [КРОЛь 1993]. Стратегии будущего должны охватывать оба модуса существования культурных единиц, один из которых базируется на архетипе обители, другой - на архетипе 
похода [ВоловиК 2012]. Основания современной концепции существования культурной единицы будут круизировать между этими «полюсами».

Обратимся к истории осмысления феномена стратегии. Иногда ее сопоставляют с искусством [АРЗУМАНЯн 2010] или даже спортом [КРЕВЕЛЬД 2005] -настолько далеко она выходит за рамки науки. Стратегия в современном понимании этого термина возникает в контексте осознанного насилия или/и противодействия ему. Материалом для исследователей чаще всего служат войны эпохи сражающихся царств Древнего Китая (VI в. до н.э.)[Сунь-Цзы 2006] или даже социальное поведение шимпанзе и других приматов (дележ лесных территорий между их стаями) [ФРИДМАН 2018].

«Лучшее пособие по стратегии последнего десятилетия в обороне, политике и бизнесе» Л. Фридмана констатирует: «лучшая стратегия ныне заключается в том, чтобы умело обернуть обстоятельства в свою пользу» [ФРИДМАН 2018: 4].

Обман актуального и возможного противника (включая сегодняшних союзников?) стал повседневностью культурных единиц «странового» уровня. Обратной стороной обмана является недоверие. Несмотря на современную практику, один из ведущих социологов современности - П. Штомпка - полагает, что шанс на возникновение общества доверия существует. И «даже если это является, возможно, новой утопией, то такой, которая достойна нашего размышления и наших усилий, которая расширяет горизонт нашей мечты о лучшем существовании общества» [ШТОМПКА 2012: 432].

Поскольку стратегия как аспект способа существования может обладать вредоносностью, «токсичностью» (по отношению как к объекту, так и к субъекту стратегии), она является объектом рассмотрения гигиены культуры. Здесь мы не выстраиваем проектов увеличения взаимного доверия между какими бы то ни было субъектами, в том числе, на «страновом» уровне. Мы исходим из предположения, что в обозримом будущем некоторая степень недоверия в глобальной системе будет присутствовать. Из этого следует, что бюджеты стран будут отвлекать немалую часть ресурсов на непроизводительные расходы - гонку вооружений, в том числе, бактериологических и вирусных, на коммуникационные и сетецентрические разрушительные средства. Но как показывает история, рано или поздно «висящее на стене ружье» стреляет, несмотря на многоуровневую защиту от случайностей. Примерами могут служить аварии на атомных электростанциях Чернобыля и Фукусимы. Открытый П. Баком закон спонтанной эволюции систем к критическому состоянию указывает на отличную от нуля вероятность подобных катастроф [БАК 2013]. Растущие информационные потоки, порождая самоорганизующиеся калейдоскопические структуры непрерывно дополняемой реальности [РЕУт 2020] увеличивают нестабильность мира.

Сетецентрические стратеги сами не защищены от фейков стратегического масштаба, например, от фейка о том, что некто отравлен в Солсбери или о том, что Россия является врагом США или/и стран Европы. Но фейки могут быть эффективным аргументом этих стратегов, например, при разделе государственных бюджетов. 
Возвращаясь к COVID-19, заметим, что если даже эта конкретная пандемия имеет естественное происхождение, множество лабораторий по разработке бактериологического и вирусного оружия, принадлежащих противостоящим друг другу военным блокам, не имеют абсолютной защиты. Случатся ли утечки? Это -вопрос времени. Но взаимное недоверие субъектов геостратегического плацдарма устанавливает предел развитию глобальной системы. Чем выше уровень недоверия и. соответственно, расходов на средства взаимного уничтожения, тем меньше средств остается на развитие и позитивное взаимодействие. Уровень недоверия между культурными единицами есть абсолютный ограничитель пределов развития сложной глобальной цивилизационно-культурной целостности.

И хотя в условиях пандемии успешными оказываются национально- и социально-ориентированные государственные образования сильной степени централизации, пока они не выходят за рамки вышесказанного.

Компетенции ЛПР включают способность оценивать последствия принимаемых решений. Существует классификация типов последствий принимаемого решения. В работе [ЩЕДРОВИЦКИй 1987: 41] рассмотрены три типа последствий: 1) контролируемые и учитываемые, 2) не контролируемые, но учитываемые, 3) не контролируемые и не учитываемые. В указанной работе обсуждается организация деятельности в каждом из перечисленных случаев. Мы предлагаем рассмотреть еще один тип последствий принимаемых решений, а именно, связанных с контролем последствий, которые невозможно заранее учесть [РЕУТ 2015]. Таков в рассматриваемой ситуации класс решений, связанных с взаимным недоверием. Возможны ли стратегии, исключающие этот класс?

Для ответа на этот вопрос обратимся к естественной истории. Как отмечалось, временной горизонт рассмотрения феномена стратегии обычно начинается с возникновения осмысленной агрессии или/и защиты от нее. Ретроспективный анализ процесса эволюции живой природы, продолженный «глубже» точки возникновения мышления (и изобретения феномена обмана), показывает, что такие стратегии возможны. Они характеризуют способ существования далеких от мышления животных, непрерывно, хотя и медленно, шлифовавшийся естественным отбором. Мыслящие существа противопоставили ему искусственный отбор, базирующийся на «лучших практиках», в частности, на более или менее искусном обмане. Вопрос о том, каким образом Homo Sapience может «вернуться» в область правдивых, альтруистических пост-прагматических стратегий, мы оставляем за рамками настоящей статьи. Но он стоит на повестке дня гигиены культуры. Сейчас мы фиксируем только, что жизнь и даже некоторые формы социальности без обмана и недоверия возможны. Чем альтруистичнее семейная пара, выкармливающая птенцов, тем вероятнее ее репродуктивный успех в стратегической перспективе.

С появлением Homo Sapience искусственный отбор посредством мышления оказался всего лишь ступенью в преобразованной форме отбора естественного.

«Природный интеллект во всей совокупности его проявлений ... изначально развивался как орган антиэнтропийной активности, способствующий добыванию свободной энергии, а также защите накопленной в организме 
энергии от притязаний извне. Убедившись же, что антиэнтропийный процесс непременно оплачивается ростом энтропии, мы вынуждены признать: интеллект по одной из своих первичных функций - инструмент агрессии. Но вместе с тем - инструмент экономии агрессии, поскольку он обеспечивал достижение целей активности меньшими энергетическими затратами» [НАЗАРЕТЯН 1996: 28 - 29]. В данной работе мы рассматриваем предельный вариант, в котором уровень агрессии снижается до нуля. К сожалению, как утверждается в исследовании [ПилЕЦКИй 2015: 462], уровень агрессивности человека с прогрессом общества не снижается.

Возможно, продвижение в направлении снижения агрессивности социума может быть получено с помощью технологии, использующей идею цикла креативности Кребса, предусматривающего циклическое обращение к категориям науки, инженерии, дизайна и искусства [РЕУТ - ПоЛОВОВА 2017]. Стратегии применимы ко всем четырем составляющим цикла Кребса. В связи с этим важны исследования социальных измерений аудитории искусства [УШКАРЕВ 2019], науки, инженерии, дизайна.

Вернемся к эпиграфу, помещенному в начале статьи. В чем заключается главный секрет? Да, лис знает много хитростей, но главная хитрость, главный секрет метафорического «ежа» применительно к обсуждаемой теме - правдивость.

Нам представляется далеко не случайным, что основоположник теории рыночного хозяйства А. Смит создал свой фундаментальный труд «Исследование о природе и причинах богатства народов» [СмиТ 2007] уже будучи автором получившей всеобщее признание «Теории нравственных чувств» [СМИТ 1997]. Можно сделать вывод, что он мыслил субъекта рыночной экономики несомненным носителем моральных качеств, в первую очередь, справедливости и правдивости, чему не должен мешать здоровый эгоизм предпринимателя. Ведь только при этих условиях рынок мог бы обеспечить всеобщую справедливость и равенство. На многочисленных примерах из истории Европы и ее колоний в программном труде [Смит 2007] автор показал, что войны и произвол властителей подрывают веру рабочих и предпринимателей в справедливость, отрицательно влияют на реальную экономику и богатство народов. А. Смит не строил безосновательных иллюзий относительно восстановления идеальных условий для рыночной экономики. «Конечно, ожидать восстановления когда-нибудь полностью свободной торговли в Великобритании так же нелепо, как ожидать осуществления в ней «Океании» или «Утопии» («Океания» - название известного сочинения Гаррингтона; «Утопия» - название сочинения Томаса Мора)» - замечал он [Смит 2007: 456].

В конце XIX в. французский микробиолог Л. Пастер излечил безнадежного больного от бешенства введением ослабленного возбудителя. Случай привлек внимание публики и прессы. В то время в стране разразилась эпидемия сибирской язвы, поражавшей скот. Ученый исследовал возбудителя этой болезни и разработал вакцину. Общественная поддержка позволила развернуть ее производство, бесплатное распространение и обучение ветеринаров. Эпидемия была побеждена. 
В 1983 г. французский социолог и философ Б. Латур опубликовал статью «Дайте мне лабораторию, и я переверну мир», в которой он на примере Пастера излагает взгляд социолога на естественные науки, изучает различия и сходства, существующие между исследованиями феноменов «макро» и «микро» уровней. Лаборатории не только получают новые знания, но и разрабатывают практические технологии. Последние влияют на процессы «макро» уровня. Латур выделяет приемы, позволяющие «лаборатории» получить поддержку общества. Но политического уровня это влияние не достигает. «Врожденным недостатком социологии науки является ее предрасположенность искать явные политические мотивы и интересы в одном из тех мест (т. е. в лаборатории), где зарождаются еще как таковые непризнанные истоки новой политики» [ЛАТур 2002: 229]. В статье представлено видение взаимосвязи и взаимозависимости проблем микро и макроуровней и методологический подход к развитию взаимодействия между ними. Однако вопросы взаимодействия исследований микроуровня скультурой в целом остаются вне поля зрения автора, поскольку он преодолевает «интерналистское» видение своей науки лишь в отношении микробиологии. Поэтому во времена Латура переопределения феномена культуры не произошло.

Ситуация c COVID-19 качественно иная. Перспективы достижения коллективного иммунитета и получения вакцины неопределены в связи с мутациями вируса. Возникают экономические трудности и локальные дефициты медицинских ресурсов. Мир захлестывают неупорядоченные информационные потоки, создаваемые калейдоскопическими структурами непрерывно дополняемой реальности. Стремительно меняется повседневность. Растет социальная напряженность. Возникают спекуляции о коронавирусе как об инструменте политики. Закрытие границ выявляет влияние культурных различий (локальных инвариантов, образующих несущий каркас) на социальные процессы. Проявляется сравнительная способность культурных единиц выживать в экстремальных условиях.

В свое время внимание прессы обеспечило Пастеру решающую поддержку общества в борьбе с эпидемией. Но сегодня полемическое заглавие статьи Латура мы не можем переформулировать в стиле «дайте мне аккаунт, и я переверну мир». Не удается априорно указать, какой твит вызовет лавину перепостов и, возможно, очередную мировую катастрофу. Мир на наших глазах перевернулся и продолжает неконтролируемо меняться.

Доверие - мощнейший ресурс культуры, позволяющий снять присущее современной эпохе фундаментальное ограничение на развитие цивилизационнокультурной общности. То, что изменение мира происходит через изменение себя - давно стало общим местом гуманистической философии. Уже принуждение к доверию дает обильные плоды. Мы полагаем, что добровольное доверие может привести к качественному росту общественной эффективности, о чем свидетельствует, в частности, опыт мировых религий.

Мы полагаем, что возможен переход, открывающий эпоху пост-прагматических стратегий культурных единиц. Стратегия может рассматриваться как стержень способа существования названной единицы и/или некоторой их совокупности, поскольку реализацией собственной стратегии 
они стремятся выстраивать свое будущее. Мы избрали названный в заглавии статьи класс стратегий в качестве предмета исследования настоящего направления работ. За очерчиванием границ класса пост-прагматических стратегий должна последовать их детализация.

В качестве одного из инструментов разработки пост-прагматических стратегий предлагается использовать модель, основанную на фундаментальной проблеме теории игр - так называемой «дилемме заключенного» [AXELROD - HAMILTON 1981]. В терминах политического реализма она именуется дилеммой безопасности [ВОOTH - WHEELER 2007]. Суть ее состоит в следующем. Игроки геополитического плацдарма стремятся наращивать вооружения в целях собственной безопасности. Это порождает недоверие других участников международных отношений и толкают их на аналогичные меры. Возникает порочный круг безопасности и накопления силы [HERZ 1950]. Использование рефлексии предоставляет субъектам политического плацдарма дополнительные инструменты анализа в процессе принятия решений [ЛЕФЕВР 2003]. С некоторых пор модель отягчается заботой о кибербезопасности.

Применительно к сложившимся условиям мы предлагаем модифицировать обсуждаемую модель введением дополнительных условий. При этом она приобретает следующий вид. Существует множество субъектов международной политики, способных создавать коалиции и совершать иные действия (набор которых можно обсуждать) в калейдоскопическом пространстве дополняемой реальности, перманентно распределяющих свои ресурсы и ежегодно распределяющих свои бюджеты пропорционально ставкам на доверие/недоверие к оппонентам в условиях роста вероятности наступления рисковых событий во внешней среде, реализующихся согласно модели песчаной кучи П. Бака [БАК 2013].

С позиций гигиены культуры мы настаиваем, что вес взаимного доверия в международных отношениях следует увеличивать. Это объективно необходимо вследствие роста вероятности наступления рисковых событий во внешней среде и мощности этих событий, а также «зашумления» информационного пространства. Оно порождается неожиданными для стратегов процессами самоорганизации окружающей их дополняемой реальности. Эти процессы инициируются за счет интенсификации пронизывающих повседневность информационных потоков.

Смысловой поток развития методологии с опорой на классификацию В.М. Розина [РОзин 2005] мы можем охарактеризовать следующим образом. Человеческая активность была отрефлектирована зачинателями методологического движения в качестве феномена системомыследеятельности (СМД) [ЩЕДРОВИЦКИй 1995]. Поскольку она представлялась участникам методологического движения центральной и, по сути, единственной заслуживающей внимания сущностью, этот период развития методологии называют пан-методологическим. Сегодня мы видим, как СМД, проходя сквозь «игольное ушко» хронотопа (понимаемого как точка пространственно-временного континуума), формирует триединство культурной единицы, ее стратегии и временно́го горизонта осуществления стратегии или последовательности стратегий, имплицитно задающего вероятную продолжительность существования 
культурной единицы. При этом единство мышления, деятельности и их системного представления сохраняется.

Хочется верить, что этот номер журнала выйдет в свет уже после преодоления гибридного кризиса-2020. Но есть основания подозревать, что он не будет последним кризисом в истории человечества. Поэтому роль гигиены культуры в завтрашнем мире сохранится и будет усиливаться.

\section{ПРИЛОЖЕНИЕ}

\section{Труды конференций и коллективные монографии по гигиене культуры}

(в хронологическом порядке)

1. Культура и гигиена. Гуманизм как потребность. Материалы круглого стола «Гигиена культуры - культурологический обзор», организованного Ассоциацией «За венгерско-российское сотрудничество им. Льва Николаевича Толстого» в Венгерском культурном центре в Москве 30 мая - 1 июня 2012 г. Будапешт: Ассоциация им. Л.Н. Толстого. Издательство Каирос. - 2012. Kultúra és higiénia. A humanizmus mint szükséglet. A Tolsztoj Társaság a Magyar-Orosz Együttmüködésért Egyesület és a Moszkvai Magyar Kulturális Központ "A kultúra higiéniája - kulturológiai áttekintés" címmel 2012. május 31 -1-n megrendezett kerekasztala anyagaiból készült tanulmánykötet. Budapest: Tolsztoj Társaság. Kairosz Kiadó. 2012. Тираж 500 экз.

2. Культура и гигиена 2. Работа продолжается. Коллективная монография // Ред.: Иштван Мадьяри-Бек и Ольга Сюч. Изд. Каирос. Будапешт, 2014. г. 561 с. Kultúra és Higiénia 2. A munka folytatódik. // Szerkesztette: Dr. Magyari Beck István, Dr. Szücs Olga. Kairosz Kiadó. Budapest, 2014. 7-8. old. 561. Тираж 500 экз.

3. Феномен одиночества. Актуальные вопросы гигиены культуры: Коллективная монография / Отв. редакторы М.В. Бирюкова, А.В. Ляшко, А.А. Никонова. - СанктПетербург: РХГА, 2014. 368 c. The Phenomenon of Loneliness. Actual Questions of Hygiene of Culture: Collective monograph// Resp. editors M.V. Biryukova, A.V. Lyashko, A. A. Nikonova, - St. Petersburg, 2014. - 368 p. Тираж 500 экз.

4. Гигиена культуры: общий концепт и виды социальных болезней: монография / колл. авторов; отв. редакторы: И. Мадьяри-Бек, Т.Н. Юдина, Т.Ю. Кирилина. Москва: РУСАЙНС, 2016. 282 c. Hygiene of culture: concept and types of social diseases: monograph / collective of authors; editors: I. Magyary-Beck, T.N. Yudina, N.Y. Kirilina. - Moscow: RU-SCIENCE, 2016. - 282 p. Тираж 500 экз.

5. Гигиена культуры: современные повседневные практики и риски: коллективная монография / отв. ред. Т.Н. Юдина, Д.К. Танатова. Москва: Издательство РГСУ, 2018. 464 с. Нуgiene of culture: today's everyday practices and risks: collective monograph / Ed. Editors: Yudina T.N., Tanatova D.K. - Moscow Publishing house of RSSU, 2018. 464 p. Тираж 500 экз.

6. Гигиена культуры. Вопросы будущего. Коллективная монография. Ассоциация им. Л.Н. Толстого - Будапешт: Издательство Каирос, 2018. 158 с. The hygiene of culture. The questions of the future. Collective monograph. Budapest: Association named after L.N. Tolstoy - Publishing house "Kairos". 2018. 134 p. Тираж 500 экз.

7. Гигиена культуры. Экспертный диалог. Коллективная монография. Ассоциация им. Л.Н. Толстого - Будапешт: Издательство Каирос, 2019. 139 с. The hygiene of culture. Expert Dialogue. Collective monograph. Budapest: Association named after L.N. Tolstoy - Publishing house "Kairos". 2019. 131 p. Тираж 500 экз. 
8. Гигиена культуры: теория, методология, практики. Коллективная монография. Москва: РГСУ, 2019, 416 с. Тираж 500 экз.

9. Основы культурной политики: аксиологический подход. Сборник трудов Международной конференции. Государственный институт искусствознания. Октябрь 2018 г. Москва: Издательство ГИИ. 2020. (электронное издание)

10. Культура в цифровом обществе - аспекты гигиены культуры. Труды Десятой (юбилейной) конференции, проводимой в рамках международного сотрудничества по новой дисциплине Гигиены культуры. Дебрецен, 17-18 октября 2019. г. Дебрецен: Русский Центр Дебреценского университета. 2020. Тираж 500 экз. (в печати)

\section{Литература}

AXELROD - HAMILTON 1981: Axelrod, Robert and Hamilton, William D. «The Evolution of Cooperation». Science, New Series, Vol. 211, No. 4489 (Mar. 27, 1981), pp. 1390-1396. ISBN $\quad 0-465-02121-2$. Stable URL: http:/links.jstor.org/sici?sici=00368075\%2819810327\%293\%3A211\%3A4489\%3C1390\%3ATEOC\%3E2.0.CO\%3B2-6 (Дата обращения 04.07.2020)

BоOTH - WheELER 2007: Booth, Ken, Wheeler, Nicholas. The Security Dilemma: Fear, Cooperation and Trust in World Politics. - First Edition, New York: Palgrave.

ChILCOAT 2001: Chilcoat, Richard A. "Strategic Art: The New Discipline for 21st Century Strategists," in U.S. Army War College Guide to Strategy, PA: Strategic Studies Institute.

GRAY 1999: Gray, Colin Modern Strategy. Oxford: Oxford University Press.

HERZ 1950: Herz, John H. Idealist Internationalism and the Security Dilemma // World Politics. V. 2, Issue 2. 157-180. - doi:10.2307/2009187.

АРзУмАНЯн 2010: Арзуманян, Р. Сложное мышление и наука сложности // 21-й век. Выпуск № 4 (16) / 2010. С. 12 - 38.http://cyberleninka.ru/article/n/slozhnoe-myshleniei-nauka-slozhnosti (Дата обращения 04.07.2020).

АРзУМАНЯн 2011: Арзуманян, Р. Сложное мышление и Сеть: парадигма нелинейности и среда безопасности XXI века / Монография. Ереван: НОФ «Нораванк». http://noravank.am/rus/books/detail.php?ELEMENT_ID=622818.01.2012.

http://csef.ru/ru/oborona-i-bezopasnost/348/rarzumanyan-slozhnoe-myshlenie-i-set-paradigma-nelinejnosti-i-sreda-bezopasnosti-xxi-veka-2512 (Дата обращения 04.07.2020).

БАК 2013: Бак, Пер. Как работает природа: теория самоорганизованной критичности. Москва: Книжный дом ЛИБРОКОМ.

Воловик 2012: Воловик, В.В. Порядок обители и порядок похода. Феноменология институционального. 2012. Сайт Фонд ГП.

URL: http://www.fondgp.ru/lib/seminars/2012-2013/xix/35 (Дата обращения 17.02.2020).

КАГАН 1966: Каган, М. Философия культуры. Санкт-Петербург: Наука.

КРЕВЕЛЬД 2005: Кревельд, М. фон «Трансформация войны». Москва: Альпина Бизнес Букс.

КрОль 1993: Кроль, Ю.Л. (отв. ред.) Книга правителя области Шан (пер. с китайского Переломов, Л.С.) Москва: Ладомир.

ЛАтур 2002: Латур, Б. Дайте мне лабораторию, и я переверну мир / Логос. 2002. 5-6 (32). 211-242.

ЛЕФЕВР 2003: Лефевр, В.А. Алгебра совести. Москва: КОГИТО-ЦЕНТР.

ЛюттвАК 2012: Люттвак, Э.Н. Стратегия. Логика войны и мира. Москва: Университет Дмитрия Пожарского. Русский Фонд Содействия Образованию и Науке.

МОРЕН 2005: Морен, Э. Метод. Природа природы / перевод с французского Е.Н. Князевой. - Москва: Прогресс-Традиция. 
НАЗАРЕТЯН 1996: Назаретян, А.П. Агрессия, мораль и кризисы в развитии мировой культуры. Москва: Наследие.

ПиЛЕЦКиЙ 2015: Пилецкий, С.Г. Каиново наследство, или Опыт изучения человеческой агрессивности: Анализ этологических, социобиологических и современных социально-гуманитарных концепций. Москва: ЛЕНАРД.

РЕУт 2015: Реут, Д.В. Контроллинг в атомной отрасли / Контроллинг, 2015/1:0 18-25.

РЕУт 2017: Реут, Д.В. От методологии до практики устойчивого воспроизводства культурной единицы на примере Европы (гигиена культуры) / Slavica 46: 124-139.

РЕут 2019а: Реут, Д.В. Методология гигиены культуры как междисциплинарного научного направления / Гигиена культуры: теория, методология, практики. Коллективная монография. / Й. Горетить, О. Сюч, Д.В. Реут и др. Москва: РГСУ.

РЕУт 2019б: Реут, Д.В. О культурных единицах и совокупностях, создаваемых ими и самовоспроизводящихся / Мир психологии, 2019/3: 69-79.

РЕут 2020: Реут, Д.В. Цифровые джунгли наступают: "квантовые скачки" сложности техногенной среды обитания современного человека/ Культура в цифровом обществе - аспекты гигиены культуры. Труды Десятой (юбилейной) конференции, проводимой в рамках международного сотрудничества по новой дисциплине Гигиены культуры. Дебрецен, 17-18 октября 2019. г. Дебрецен: Русский Центр Дебреценского университета. (в печати).

РЕут - ПолОвовА 2017: Реут, Д.В., Половова, В.С. Цикл Кребса: новая семиотическая машина креативности / Мир психологии, 2017/2: 218-231.

РОзИн 2005: Розин, В.М. Методология: становление и современное состояние. Москва: Московский психолого-социальный институт.

Смит 1997: Смит, А. Теория нравственных чувств. Москва: Республика.

Смит 2007: Смит, А. Исследование о природе и причинах богатства народов. Москва: Эксмо.

Сунь-цзы 2006: Сунь-цзы. Искусство стратегии. Москва: Издательство Эксмо; СанктПетербург; Мидгард.

ТОФФЛЕР 2005: Тоффлер, Э. Война и антивойна. Москва: АСТ.

УШКАРЕВ 2019: Ушкарев, А.А. Аудитория искусства в социальных измерениях. СанктПетербург: Алетейя.

ФРидМАН 2018: Фридман, Л. Стратегия: война, революция, бизнес. Москва: Кучково поле.

ХАНТингтОН 2003: Хантингтон, С. Столкновение цивилизаций. Москва: ООО «Издательство АСТ».

ШТОМПКА 2012: Штомпка, П. Доверие - основа общества. Москва: Логос.

ЩЕДРОВИЦКиЙ 1987: Щедровицкий, П.Г. Деятельностно-природная система / "Человек и природа", Москва, "Знание", 1987/12: 12-63 http://www.shkp.ru/lib/publications/11 (Дата обращения 04.07.2020).

ЩЕдРОВИцкий 1995: Щедровицкий, Г.П. Избранные труды. - Москва: Школа культурной политики.

Дмитрий РЕУТ

Московский государственный технический университет им. Н.Э. Баумана reut@bmstu.ru

Национальный исследовательский ядерный университет (МИФИ) dmreut@gmail.com

Московский педагогический государственный университет dv.reut@mpgu.su

ORCID ID: 0000-0003-3577-7373 